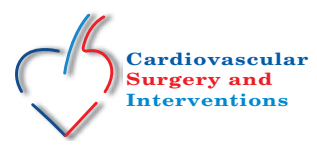

\title{
Left ventricular apical diverticulum associated with double outlet right ventricle
}

Onur Işık, Muhammet Akyüz, Mahir Balakishiev, Mehmet Fatih Ayık, Yüksel Atay

Received: July 18, 2014 Accepted: December 20, 2014 Published online: February 10, 2015

A six-year-old boy was admitted to our hospital for surgery for cardiac anomaly. The patient's medical history included a right $5 \mathrm{~mm}$ sided modified Blalock-Taussig shunt through median sternotomy incision. Physical examination was normal, except a pulsatile mass localized in the epigastric area starting near inferior portion of the xiphoid process. Transthoracic echocardiography revealed double outlet right ventricle, subaortic ventricular septal defect, pulmonary stenosis, and patent right-sided shunt. An outpouching in the left ventricle apex which freely communicated with the left ventricle cavity through a narrow neck was observed. The diverticulum showed characteristics synchronous contractility with the left ventricle. The patient had normal left ventricular function without any evidence of thrombus in the left ventricular cavity or diverticulum. Cardiac computed tomography images revealed focal outpouching in the apical wall of the left ventricle, consistent with a congenital muscular diverticulum of the left ventricle apex (Figure 1). The patient was operated through re-median sternotomy incision and the apical diverticulum was visualized (Figure 2). After initiating cardiopulmonary bypass, Rastelli procedure was performed. At the end of the procedure, the left ventricular diverticulum was resected and primarily closed.

\section{CASE REPORT}

Although congenital diverticulum of the left ventricle $(\mathrm{LV})$ is a rare cardiac malformation, comorbid disorders may frequently coexist. ${ }^{[1]}$ The incidence of $\mathrm{LV}$ diverticulum has been reported to be $0.05 \%$ of all congenital heart malformations. ${ }^{[2]} \mathrm{A}$ diverticulum is typically characterized by a morphologically narrow neck and synchronous contractility. ${ }^{[3]}$ Both LV aneurysm and pseudoaneurysm which are characterized by a wide neck and paradoxical contraction. ${ }^{[3]}$ Most of the left ventricular diverticula are located at the apex of the LV, however, they may also be found in
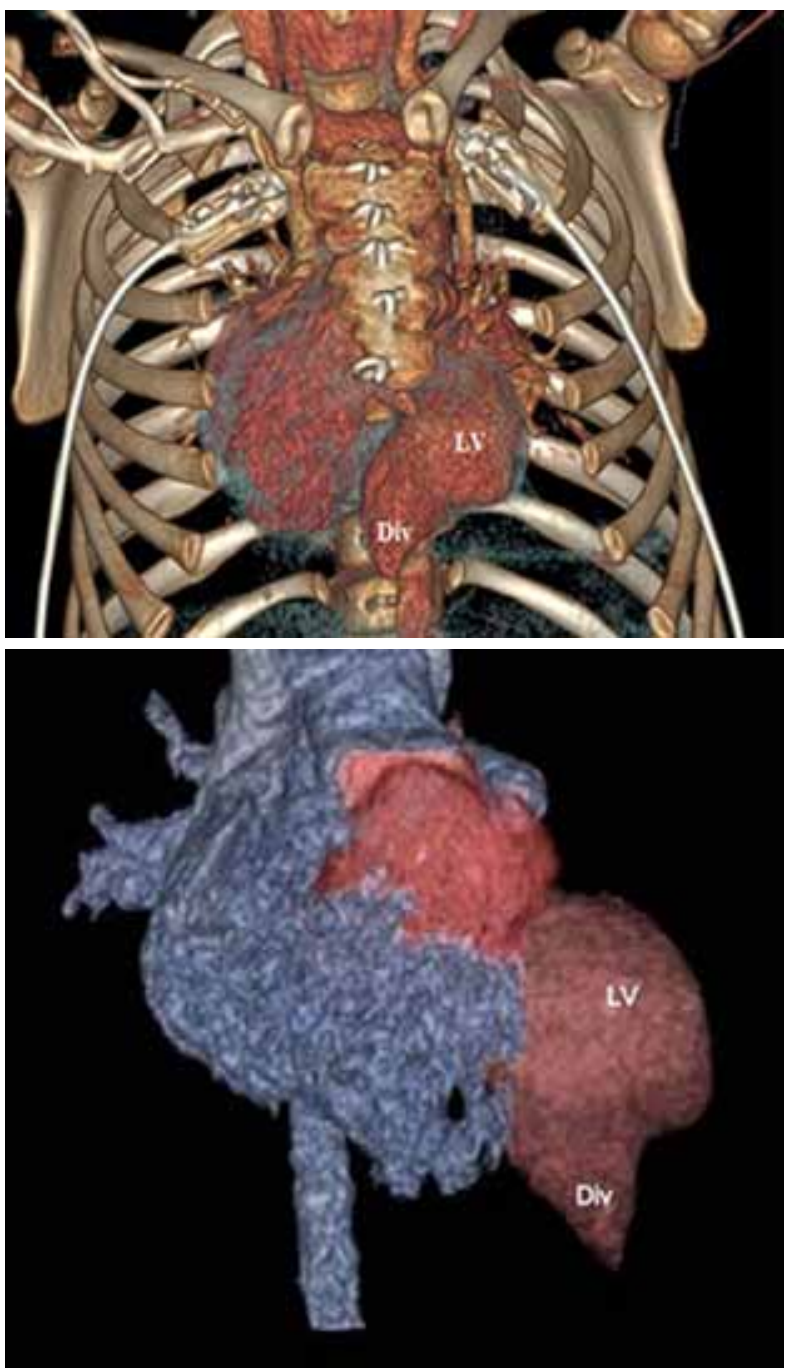

Figure 1. Three-dimensional computed tomography reconstruction of the heart showing diverticulum in the apical wall of the left ventricle. LV: Left ventricle; Div: Diverticulum.

Department of Cardiovascular Surgery, Medical Faculty of Ege University, İzmir, Turkey

Corresponding author: Muhammet Akyüz, M.D. Ege Üniversitesi Tip Fakültesi Kalp ve Damar Cerrahisi Anabilim Dalı, 35100 Bornova, İzmir, Turkey.

Tel: +90 232 - 3881115 e-mail: drmak100@gmail.com 


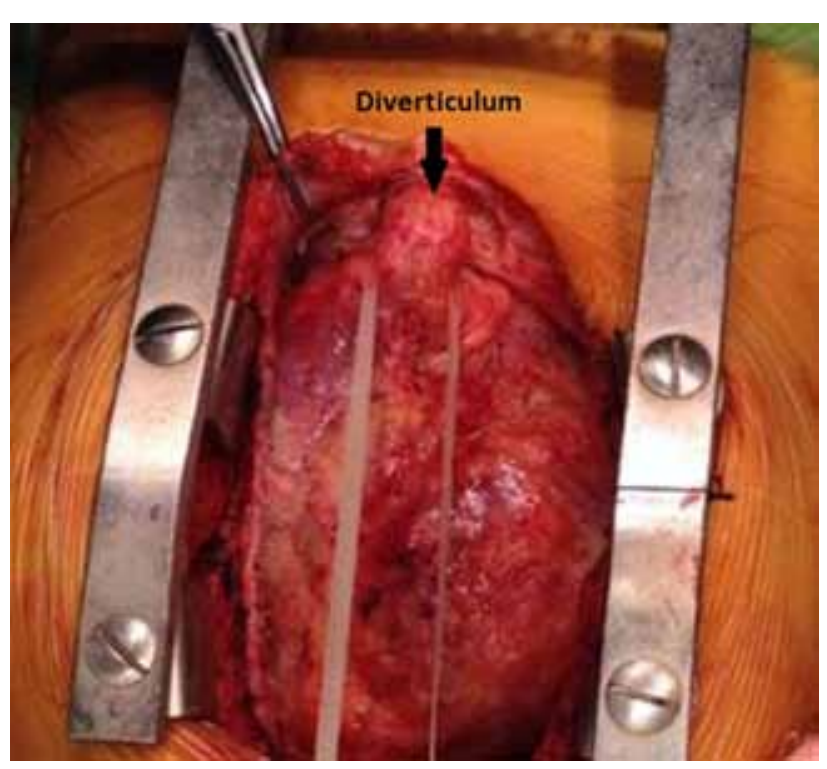

Figure 2. Operative picture of the diverticulum (arrow) at the apex of the heart.

any other location and may occur in association with cardiac heart disease, and/or extra-cardiac defects (Cantrell's syndrome). ${ }^{[3,4]}$ Congenital LV diverticula may cause serious complications including systemic thromboembolism, endocarditis, cardiac rupture, heart failure, arrhythmia, and sudden cardiac death. ${ }^{[4]}$ Asymptomatic isolated diverticulum can be followed up, but symptomatic cases or patients for whom surgical intervention is necessary, diverticulum must be repaired.

\section{Declaration of conflicting interests}

The authors declared no conflicts of interest with respect to the authorship and/or publication of this article.

\section{Funding}

The authors received no financial support for the research and/or authorship of this article.

\section{REFERENCES}

1. Saedi S, Salehi A, Saedi T, Hashemi MJ. Association of left ventricular diverticula and sinus venosus atrial septal defect. Congenit Heart Dis 2013;8:145-8.

2. Shauq A, Agarwal V, Crawley C. Congenital left ventricular diverticulum. Heart Lung Circ 2006;15:272-4.

3. Tullu MS, Vaideeswar P, Deshmukh CT. Congenital left ventricular diverticula. International Journal of Cardiology 2000;73:293-5.

4. Oylumlu M, Yüksel M, Yıldız A, Bilik MZ. Case images: A giant congenital left ventricular diverticulum. Turk Kardiyol Dern Ars 2014;42:585. 